\title{
A Case of Drug-Induced Hepatitis due to Lenalidomide
}

\author{
M.-C. Zanella ${ }^{\mathrm{a}} \quad$ L. Rubbia-Brandt ${ }^{\mathrm{b}} \quad$ E. Giostra ${ }^{\mathrm{a}}$ \\ Y. Chalandon ${ }^{c} \quad$ A. Hadengue ${ }^{a} \quad$ L. Spahr ${ }^{\mathrm{a}}$
}

Departments of a Gastroenterology and Hepatology, ${ }^{\mathrm{b}} \mathrm{Clinical}$ Pathology and

'Hematology, University Hospitals, Geneva, Switzerland

\section{Key Words}

Drug-induced liver injury · Lenalidomide · Liver biopsy · Multiple myeloma ·

Transaminases

\begin{abstract}
Lenalidomide is a recent thalidomide analog used for the treatment of refractory multiple myeloma. The main toxicity of this drug consists in severe neutropenia and thrombocytopenia. Lenalidomide-associated liver injury is rare, manifesting itself as elevated liver enzymes and hyperbilirubinemia reversible upon weeks after drug withdrawal. We report here in detail the clinical course as well as the biological and histological alterations of an acute lenalidomide-induced liver injury. Findings on liver biopsy allowed us to discriminate acute inflammatory changes due to the drug and minor associated lesions of graft-versus-host disease in this patient with recurrent myeloma after allogeneic bone marrow transplantation.
\end{abstract}

\section{Introduction}

Lenalidomide is a thalidomide analog used for the treatment of myelodysplastic syndromes, with pleiotropic activities including induction of apoptosis, inhibition of angiogenesis and broad immunomodulatory effects [1]. It has been approved by the Food and Drug Administration (FDA) in the United States and by the European Medicines Agency (EMEA) in 2007 for the use in combination with dexamethasone in the treatment of relapsed or refractory multiple myeloma [2]. This association has been well tolerated, more effective than thalidomide plus dexamethasone and less frequently associated with peripheral neuropathy in a recent case-control study [3]. The main toxicity of lenalidomide consists in myelosuppression with severe neutropenia and thrombocytopenia in approximately 60 and $30 \%$ of cases, and venous thromboembolism in about $10 \%$ of 222 patients taking lenalidomide $30 \mathrm{mg}$ daily [1]. Nonhematologic grade 3 and 4 toxicity includes fatigue, muscle weakness, skin rash, and elevated liver enzymes in $3 \%$ of patients under lenalidomide $25 \mathrm{mg}$ daily in association with 


\begin{tabular}{l|l|l|l}
$\begin{aligned} \text { Case Reports in } \\
\text { Gastroenterology }\end{aligned}$ & $\begin{array}{l}\text { Case Rep Gastroenterol 2011;5:217-222 } \\
\text { DOI: 10.1159/000326935 }\end{array}$ & $\begin{array}{l}\text { Published online: } \\
\text { April 13, 2011 }\end{array}$ & $\begin{array}{l}\text { O 2011 S. Karger AG, Basel } \\
\text { ISSN 1662-0631 } \\
\text { www.karger.com/crg }\end{array}$ \\
\hline
\end{tabular}

dexamethasone [4]. Lenalidomide has been associated with marked elevation in liver enzymes and hyperbilirubinemia reversible upon weeks after drug withdrawal $[5,6]$, but a detailed description of histological lesions has never been reported so far. We report here a detailed clinical, biological and histological observation of acute hepatitis in a patient taking lenalidomide.

\section{Case Report}

A 50-year-old man had a multiple myeloma diagnosed in January 2008 for which he initially received radiotherapy, surgery and chemotherapy with bortezomib and dexamethasone. Due to disease progression, he was treated in August 2008 with lenalidomide $25 \mathrm{mg}$ daily that was stopped after 3 months due to a severe skin rash with angioedema that reversed 4 weeks after the drug was stopped. During this period, liver function tests remained normal. In November 2008, he received autologous stem cell transplantation that induced disease remission until September 2009, when he presented with recurrent bone lesions and light chain deposition. Chemotherapy including cyclophosphamide, thalidomide and dexamethasone was associated with a decrease in light chain production but did not affect bone lesions, which increased in size. Thus stem cell therapy was again considered and an allogeneic transplantation was performed on March 2010 after conditioning with melphalan, anti-lymphocyte globulin, fludarabine and prednisolone. To prevent graft-versus-host disease (GVH), cyclosporine and mycophenolate mofetil were administered. During this period, liver transaminases remained below two times the upper limit of normal. Other routine daily medications included acetylsalicylic acid $100 \mathrm{mg}$, penicillin $1 \mathrm{mIU}$, ursodeoxycholic acid $750 \mathrm{mg}$, esomeprazole $40 \mathrm{mg}$, valacyclovir $500 \mathrm{mg}$, as well as trimethoprim $80 \mathrm{mg}$ + sulfamethoxazole $400 \mathrm{mg}$ three times a week.

On July 19, the patient was again started on lenalidomide $10 \mathrm{mg}$ daily for recurrent myeloma lesions in the lumbar spine, without clinical allergic manifestations. He did not complain of fever, digestive symptoms or skin lesions and declared no alcohol or illicit drug consumption. Routine laboratory tests performed on July 28 showed the following: aspartate aminotransferase (AST) 246 IU/1 (normal <50), alanine aminotransferase (ALT) $509 \mathrm{IU} / \mathrm{l}$ (normal <50), alkaline phosphatase $198 \mathrm{IU} / \mathrm{l}$ (normal <125), gamma-glutamyl transferase $105 \mathrm{IU} / \mathrm{l}$ (normal $<40$ ), and normal serum bilirubin level. At ultrasonography, the liver appeared slightly hyperechoic with patent portal and hepatic veins. Lenalidomide was immediately stopped, but the remaining treatment was continued, and a liver biopsy was scheduled for August 5. On admission, the patient had no fever and no skin lesions. The right hypochondrium was mildly tender at abdominal palpation, but there was no spleen enlargement. Laboratory values were as follows: white blood cells $5.6 \times 10^{9} / 1$ (normal 4.11 ) with $24 \%$ eosinophils, platelet count was $167 \times 10^{9} / \mathrm{l}$, C-reactive protein $2.1 \mathrm{mg} / \mathrm{l}$ (normal $<10$ ), serum creatinine $114 \mu \mathrm{mol} / \mathrm{l}$ (normal 62-106), AST 66 IU/l, ALT 219 IU/l, alkaline phosphatase 157 IU/l, gamma-glutamyl transferase $67 \mathrm{IU} / \mathrm{l}$, with normal serum bilirubin, INR and factor V values. Serological tests for hepatitis A, B, C, E, cytomegalovirus, HIV 1 and 2, Epstein-Barr and Herpes viruses were negative. The liver biopsy showed prominent portal and lobular inflammation with a mixed cellular infiltrate rich in polynuclear eosinophils, lobular areas of confluent necrosis, and mild lesions of endothelitis and occasional biliary cell dystrophy in some portal tracts. There was no histological evidence of veno-occlusive disease at Gomori staining, iron overload, or infiltration by myeloma cells. In situ hybridization staining for cytomegalovirus and Epstein-Barr viruses was negative. Considering the presence of acute portal and lobular alterations associated with numerous polynuclear eosinophils on the one hand and the rare lesions of endothelitis and biliary cell dystrophy on the other, we made a diagnosis of acute hepatitis associated with mild degree of hepatic GVH.

Following withdrawal of lenalidomide, biological alterations returned to normal after one month, on August 31. The patient was strongly recommended to avoid lenalidomide re-exposure. Figure 1 illustrates the clinical and biological course of the acute hepatitis, while histological alterations are depicted in figure 2. 


\section{Discussion}

Reported cases of lenalidomide hepatitis are very rare with regards to the popularity of this drug for patients with multiple myeloma. Manifestations of this drug-induced hepatitis consist in elevated liver enzymes that may be associated with hyperbilirubinemia, and these changes have been reversible within weeks following discontinuation of the drug $[5,6]$. In our patient, a role for lenalidomide in the development of acute hepatitis is supported by the pattern of lesions found on the biopsy performed early in the course of the disease. Areas of confluent necrosis in the liver lobule together with inflammatory changes containing polynuclear eosinophils are elements that raise the suspicion of drug-induced liver injury [7]. Another key factor in establishing the cause of liver injury is the temporal relationship between administration of the drug and manifestations of symptoms, but other factors such as exclusion of alternative diagnoses and normalization of laboratory values after withdrawal are also considered [8]. In our patient, we used drug-induced liver injury diagnostic scales to assess the strength of the association $[9,10]$. The likelihood of a causal association between lenalidomide and the acute hepatitis ranged from 'probable' [9] to 'highly probable' [10]. In our patient, liver injury was apparently not dose-dependent, not predictable, and should be considered as an idiosyncratic toxic liver disease. It is likely that the skin rash and edema following the first exposure to lenalidomide played a role of sensitization to the drug, followed by severe liver injury after re-exposure. However, this cannot be considered stricto sensu as a positive rechallenge when determining the level of causality [9].

Interpretation of abnormal liver function tests is challenging in a patient who has both cancer and who has received bone marrow transplantation [11]. In this setting, numerous etiologies must be considered, including recurrent neoplasia, iron overload, infections, $\mathrm{GVH}$ and veno-occlusive disease as well as drug-induced liver injury. Abnormal liver function tests related to drug hepatotoxicity have been observed in $24 \%$ of patients who underwent allogeneic bone marrow transplantation, while the cause was attributed to GVH and iron overload in $38 \%$ of cases [11]. In the present observation, the liver biopsy allowed us to discriminate minor alterations of small bile ducts and rare lesions of endothelitis suggesting GVH, from the acute liver injury that was strongly suggestive of drug-induced hepatitis.

Drug-induced hepatitis may show different types of liver damage. In our patient, the pattern was predominantly cytolytic associated with an immuno-allergic type of inflammation which we attributed with relative confidence to lenalidomide. Although severe hepatotoxicity due to chemotherapeutic agents is relatively rare as compared to other drugs [8], the possibility of acute drug-induced hepatitis must always be considered, and a liver biopsy should be discussed whenever it turns to impact the patient's management.

\section{Disclosure Statement}

The authors who have taken part in this study declare that they do not have anything to disclose with regard to funding or conflict of interest with respect to this paper. 


\begin{tabular}{|c|c|c|}
\hline Case Reports in & \begin{tabular}{|l} 
Case Rep Gastroenterol 2011;5:217-222 \\
DOl: 10.1159/000326935
\end{tabular} & \begin{tabular}{|l} 
Published online: \\
April 13, 2011
\end{tabular} \\
\hline
\end{tabular}

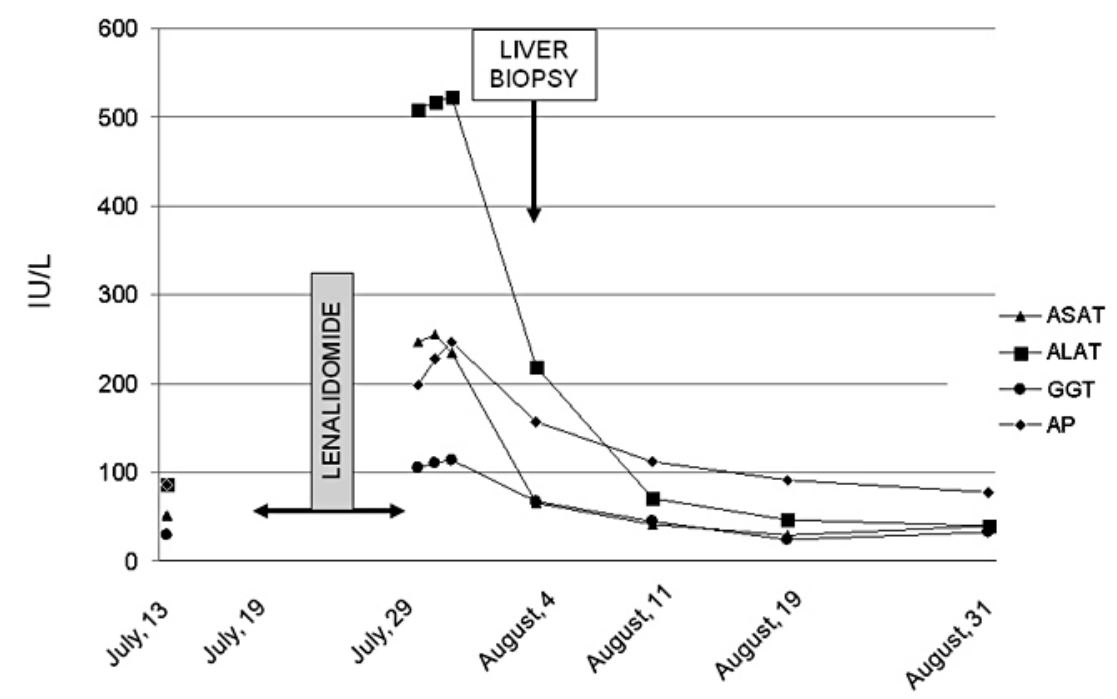

Fig. 1. Graphical illustration of liver function test alterations following lenalidomide exposure. ASAT = Aspartate aminotransferase; ALAT = alanine aminotransferase; GGT = gamma-glutamyl transferase; $\mathrm{AP}=$ alkaline phosphatase. 


\begin{tabular}{r|l|l|l} 
Case Reports in & $\begin{array}{l}\text { Case Rep Gastroenterol 2011;5:217-222 } \\
\text { DOI: 10.1159/000326935 }\end{array}$ & $\begin{array}{l}\text { Published online: } \\
\text { April 13, } 2011\end{array}$ & $\begin{array}{l}\text { @ 2011 S. Karger AG, Basel } \\
\text { ISSN 1662-0631 } \\
\text { www.karger.com/crg }\end{array}$ \\
\hline
\end{tabular}

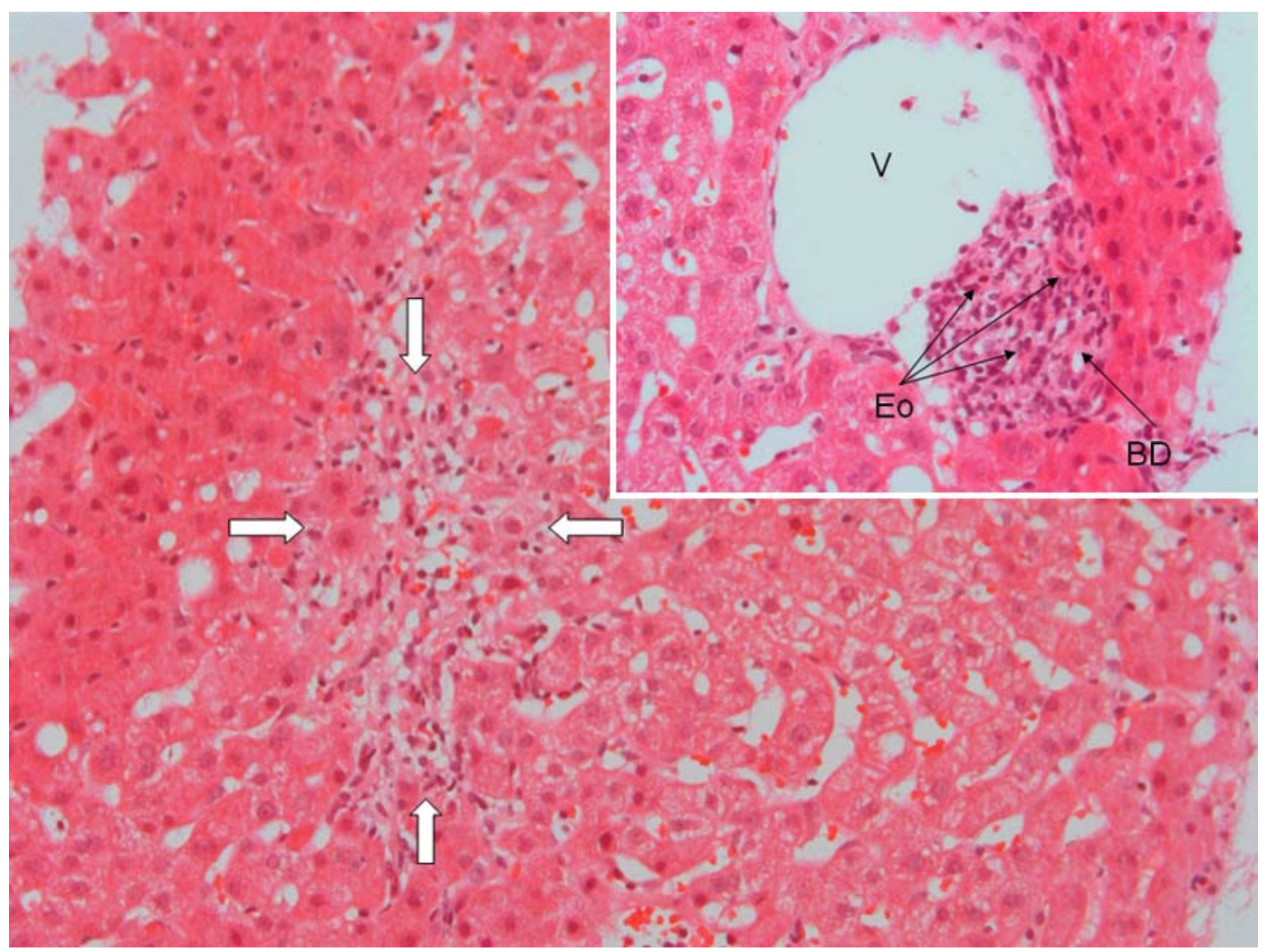

Fig. 2. Histological view (hematoxylin-eosin stain, original magnification $\times 200$ ) showing focal confluent necrosis in the liver lobule (white arrows). Inset: View of a portal tract with marked inflammation containing numerous polynuclear eosinophils (Eo), associated with biliary cell dystrophy $(\mathrm{BD})$ and mild endothelitis of the portal vein $(\mathrm{V})$ (original magnification $\times 400$ ).

\section{References}

-1 Richardson PG, Weller E, Lonial S, Jakubowiak AJ, Jagannath S, Raje NS, Avigan DE, Xie W, Ghobrial IM, Schlossman RL, Mazumder A, Munshi NC, Vesole DH, Joyce R, Kaufman JL, Doss D, Warren DL, Lunde LE, Kaster S, Delaney C, Hideshima T, Mitsiades CS, Knight R, Esseltine DL, Anderson KC: Lenalidomide, bortezomib, and dexamethasone combination therapy in patients with newly diagnosed multiple myeloma. Blood 2009;116:679-686.

2 Engelhardt M, Kleber M, Udi J, Wasch R, Spencer A, Patriarca F, Knop S, Bruno B, Gramatzki M, Morabito F, Kropff M, Neri A, Sezer O, Hajek R, Bunjes D, Boccadoro M, Straka C, Cavo M, Polliack A, Einsele H, Palumbo A: Consensus statement from European experts on the diagnosis, management, and treatment of multiple myeloma: from standard therapy to novel approaches. Leuk Lymphoma 2010;51:1424-1443.

-3 Gay F, Hayman SR, Lacy MQ, Buadi F, Gertz MA, Kumar S, Dispenzieri A, Mikhael JR, Bergsagel PL, Dingli D, Reeder CB, Lust JA, Russell SJ, Roy V, Zeldenrust SR, Witzig TE, Fonseca R, Kyle RA, Greipp PR, Stewart AK, Rajkumar SV: Lenalidomide plus dexamethasone versus thalidomide plus dexamethasone in newly diagnosed multiple myeloma: a comparative analysis of 411 patients. Blood 2010;115:1343-1350.

-4 Rajkumar SV, Hayman SR, Lacy MQ, Dispenzieri A, Geyer SM, Kabat B, Zeldenrust SR, Kumar S, Greipp PR, Fonseca R, Lust JA, Russell SJ, Kyle RA, Witzig TE, Gertz MA: Combination therapy with lenalidomide plus dexamethasone (Rev/Dex) for newly diagnosed myeloma. Blood 2005;106:4050-4053.

-5 Jain P: Lenalidomide-induced acute liver failure. Blood Transfus 2009;7:335-336; author reply 337.

6 Hussain S, Browne R, Chen J, Parekh S: Lenalidomide-induced severe hepatotoxicity. Blood 2007;110:3814.

7 Watkins PB, Seeff LB: Drug-induced liver injury: summary of a single topic clinical research conference. Hepatology 2006;43:618-631. 


\begin{tabular}{c|l|l|l}
$\begin{aligned} \text { Case Reports in } \\
\text { Gastroenterology }\end{aligned}$ & $\begin{array}{l}\text { Case Rep Gastroenterol 2011;5:217-222 } \\
\text { DOl: 10.1159/000326935 }\end{array}$ & $\begin{array}{l}\text { Published online: } \\
\text { April 13, 2011 }\end{array}$ & $\begin{array}{l}\text { O 2011 S. Karger AG, Basel } \\
\text { ISSN 1662-0631 } \\
\text { www.karger.com/crg }\end{array}$ \\
\hline
\end{tabular}

8 Bjornsson E: Review article: drug-induced liver injury in clinical practice. Aliment Pharmacol Ther 2010;32: 3-13.

9 Maria VA, Victorino RM: Development and validation of a clinical scale for the diagnosis of drug-induced hepatitis. Hepatology 1997;26:664-669.

10 Danan G, Benichou C: Causality assessment of adverse reactions to drugs - I. A novel method based on the conclusions of international consensus meetings: application to drug-induced liver injuries. J Clin Epidemiol 1993;46:1323-1330.

-11 Ho GT, Parker A, MacKenzie JF, Morris AJ, Stanley AJ: Abnormal liver function tests following bone marrow transplantation: aetiology and role of liver biopsy. Eur J Gastroenterol Hepatol 2004;16:157-162. 